\title{
A SIMPLE PDP15 INTERFACE FOR THE \\ VERSATEC SERIAL PRINTER ${ }^{\text {(a) }}$
}

\section{$\frac{2 \pi / 6}{9}$ \\ Battelle}

Pacific Northwest Laboratories

Richland. Washington 99352

This report is intended primarily for internal use by the sponsoring organization and Battelle.

Prepared for the U.S. Atomic Energy 


\section{DISCLAIMER}

This report was prepared as an account of work sponsored by an agency of the United States Government. Neither the United States Government nor any agency Thereof, nor any of their employees, makes any warranty, express or implied, or assumes any legal liability or responsibility for the accuracy, completeness, or usefulness of any information, apparatus, product, or process disclosed, or represents that its use would not infringe privately owned rights. Reference herein to any specific commercial product, process, or service by trade name, trademark, manufacturer, or otherwise does not necessarily constitute or imply its endorsement, recommendation, or favoring by the United States Government or any agency thereof. The views and opinions of authors expressed herein do not necessarily state or reflect those of the United States Government or any agency thereof. 


\section{DISCLAIMER}

Portions of this document may be illegible in electronic image products. Images are produced from the best available original document. 


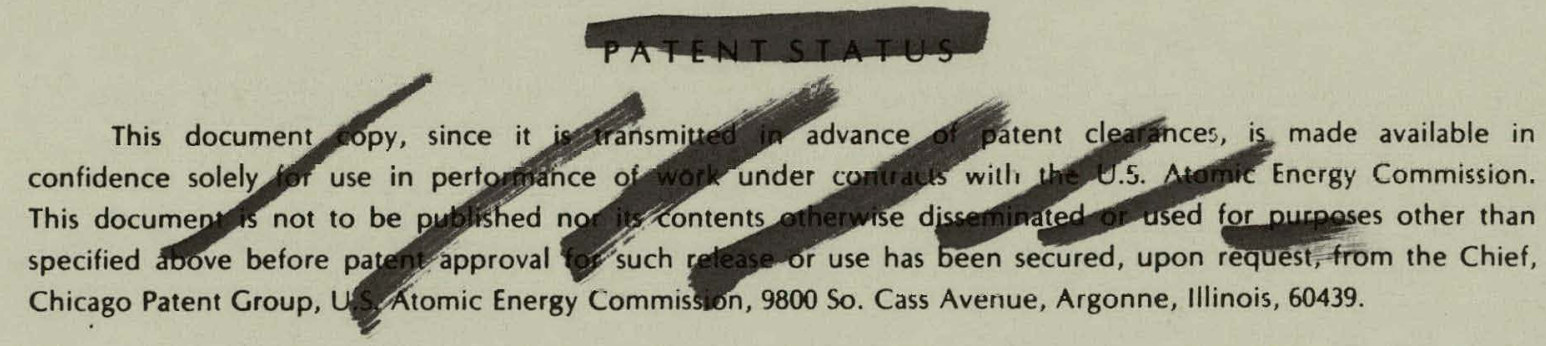

PRELIMINARY REPORT

This report contains information of a preliminary nature prepared in the course of work under Atomic Energy Commission Contract AT(45-1)-1830. This information is subject to correction or modification upon the collection and evaluation of additional data.

\title{
NOTICE
}

The report was prepared as an account of work sponsored by the United States Government. Neither the United States nor the United States Atomic Energy Commission, nor any of their employees, nor any of their contractors, subcontractors, or their employees, makes any warranty, express or implied, or assumes any legal liability or responsibility for the accuracy, completeness or usefulness of any information, apparatus, product or process disclosed, or represents that its use would not infringe privately owned rights.

\author{
PACIIIC NORTHWEST LABORATORY \\ operated by \\ BATTELLE \\ for the \\ U.S. ATOMIC ENERGY COMMISSION \\ Under Contract AT(45-1)-1830
}




\title{
A SIMPLE PDP15 INTERFACE FOR THE
}

VERSATEC SERIAL PRINTER (a)

\section{J. R. Kosorok}

Radiological Sciences Department

\section{January 1974}

\author{
Battelle \\ Pacific Northwest Laboratories \\ Richland, Washington

(a) This paper is based on work performed under united states Atomic Energy Commission Contract AT (45-1)-1830. sponsored by the United States Government. Nerer the United States nor the United States Atomic Eny of Commission, nor any of their employees, nor any their contractors, subcontractors, or their empes any makes any warranty, express or implied, or assucy com-

legal liability or responsibility for the accuracy, cotus,

pleteness or usefulness of any information, appats use

product or process disclosed, or represents would not infringe privately owned rights. 


\section{TABLE OF CONTENTS}

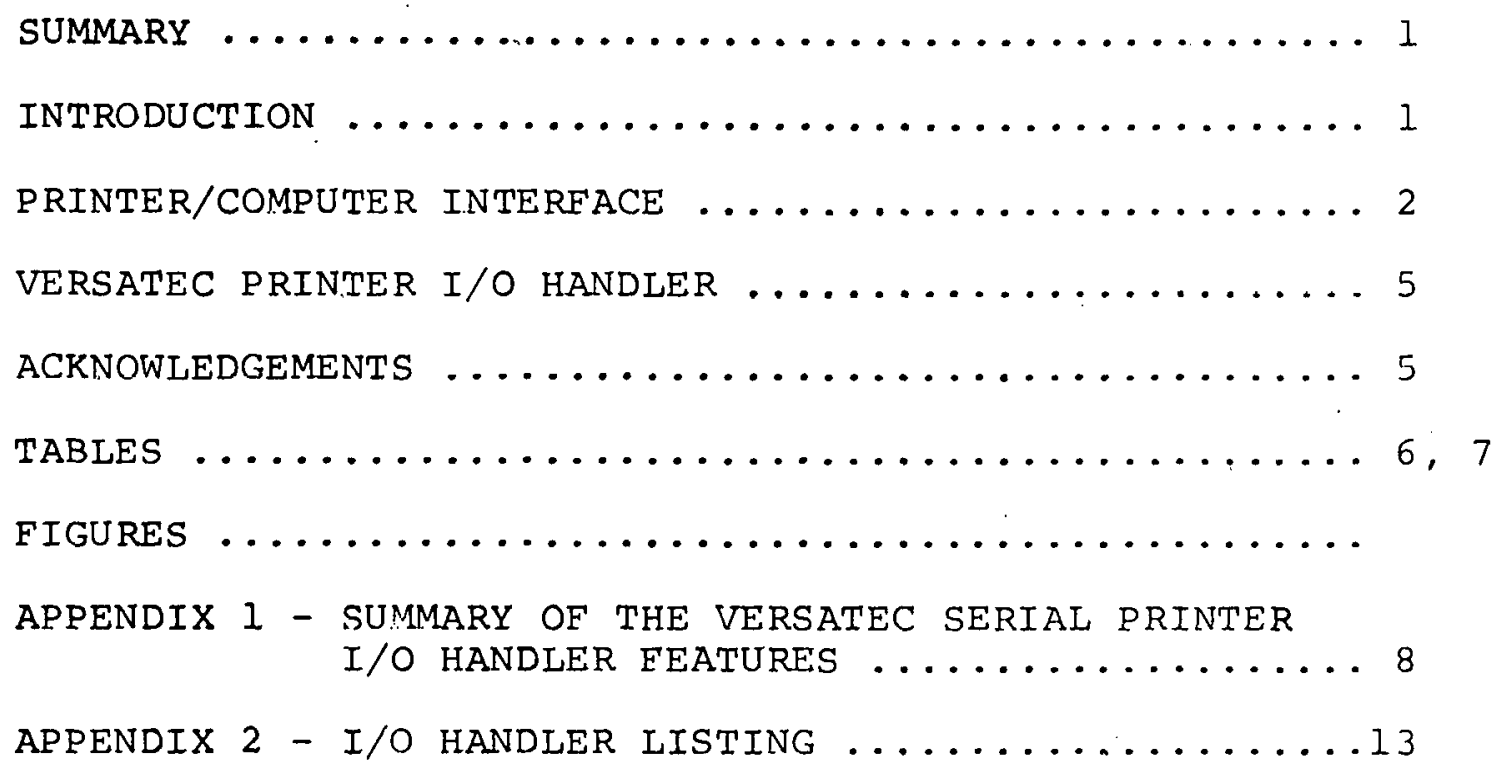


A SIMPLE PDP15 INTERFACE FOR THE

VERSATEC SERIAL PRINTER (a)

\section{J. R. Kosorok}

\section{Battelle}

Pacific Northwest Laboratories

Richland, Washington 99352

We have developed an interface between the PDP 15/30 computer and the Versatec printer/plotter, model $200 \mathrm{~A}$, operating in the serial print mode. The interface construction involved fabricating a cable with two twisted pairs for a signal and a control line, speeding up the clock in the existing foreground teletype controller and changing less than a dozen wires in it. The associated I/O device handler, which we have written, allows the printer to be used as the listing device in the Digital Equipment Corporation Advanced Monitor. Software System. With the handler, the printer is capable of printing 80 character lines at approximately 120 lines per minute.

\section{INTRODUCTION}

We have a nigital Equipment Corporation (DEC) PDP 15/30 computer system which has the equipment configuration listed in Table I. In our application we do not use the foreground teleprinter, so its controller is available for other applications.

(a) This paper is based on work performed under United States Atomic Energy Commission Contract AT(45-1)-1830. 
We also have a Versatec printer/plotter, model 200A, which was purchased for gèneral laboratory use. We determined that with a few simple modifications, the foreground teletype controller in the PDPI5 could be used as a controller for the printer portion of the versatec and immediately give us a fast printer for the PDP15. Within a few days after deciding to modify the teletype controller, we completed the design, installation and debugging of the modification and then completed a handler that operates under the Advanced Softiware system (ADSS). The Versatec printer/ plotter is currently being used as the listing device for the PDP15, printing 80 character lines at approximately 1201 ines per minute.

\section{Printer/Computer Interface}

The interface design required the addition of a jumper in one of the Versatec signal connectors, construction of a signal and control cable with two twisted wire pairs and slight modification of the PDPI5 foreground teletype controller.

Table 2 shows the Versatec connector pin assignments used for thc interface. The ilumenclature in the table is from the versatec prints. Pin 13 of $\mathrm{Jl}$ has to be true (high TTL level) for parallel plotter operation and false (ground) for serial printer operation. The Versatec printer is kept in the serial mode by a mating connector on $\mathrm{J} 1$ that has pin 13 jumped to pin 20 .

The signal and control cable for the interface has a mating connector for the Versatec serial input (J3 of Table 2) on one end and a cable card (DEC M-series M904) on the other end. The serial elevenbit code is transmitted to pin 3 of. J3 (Signal) of the Versatec via 
a twisted pair in the cable, and the REDY control is transmittec? from pin 25 of $J 3$ of the Versatec via the other twisted pair in the cable. Figure 1 shows the wiring for the PDP-15 end of the interface cable. Signal and chassis ground on the M 904 card are on pins $T l$ and $C 2$. The mounting panel slot for the $\mathrm{M} 904$ is wixed with ground on $\mathrm{Tl}$ and $\mathrm{C} 2$.

The foreground teletype controller is called the LT 15-A single Teletype control by DEC and is mounted in their BA 15, Cr: option. The schematics for the BA 15 and the LT 15 are found in Volume 2, Engineering Drawings, of the PDP - 15 Maintenance Manual.

The M 904 cable card (Figure 1) on the PDp-15 side of the interface cable is plugged into slot B31 of the BA 15, a spare slot that is unused by DEC. Figures $1,2 . a .$, and $2 . b$ in this report, as

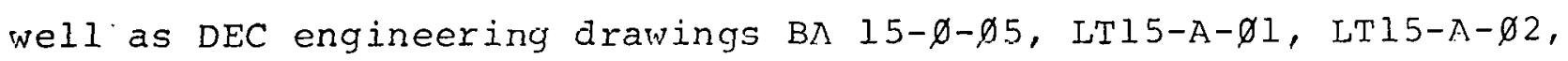
and LT15-A-Ø3 will be used to describe the modifications that we made.

The frequency of the LTI5 clock, which is an M452 module, shom in print LT15-A- $\varnothing 2$, was increased from $880 \mathrm{HZ}$ to $19,200 \mathrm{HZ}$.

Serial data, an eleven-bit ASCIJ code, appears at pin AD2 of the M707 (Figure 2.a) and is wired to pin Dl of the M904 cable board (Figure 1). REDY, the Versatec control signal (Figure 1) is connected to two gates in the modified LTl5 (Figure 2.a). REDY is true (positive TTL level) when the Versatec can accept a serial character for printing, and false (ground) otherwise.

Originally, two control signals, "LTø3 Teleprinter Flag" and "ITø3 TTU Skip" provided the PDP-15 with information on the status of the LTl5 printer corlrol operation. One signal, which appears at pin BK2(see Figure 2.a and DEC print LT15-A-Ø3), and is called "LT03 Teleprinter Flag" on print LT15-A-ø3, falls from a TTL positive 
level to ground at the heginning of the ston hits in a serial character transmission. This was inverted and then connected to an M104 module, shown in print ITI5-A-Ø1, to interrupt the PDP-15 when a character had been transmitted. For the Versatec, the LT15 is modified so that the signal at BK2 of the M707 module of Figure 2.a is inverted, combined with REDY in the logical AND gate formed by the NAND gates on the MI13 modules in slots B30 and 29, and then applied to the MlO4 module in place of the inverted "LTø3 Teleprinter Flag". Thus, when the LTI5 is finished transmitting a character code, and the Versatec is ready to accept another code, the PDP-15 is interrupted.

"LT03 TTO SKIP" was originally generated in the LTI5 (DEC print LT15-A- Ø3) whenever: 1) a test instruction was issued by the PDP15, and 2) the M707 was finished transmitting the code for a character. Tochange this for Versatec operation, "LTø3 TTO SKIP has been removed from the BAI5 and is inverted and combined in the NAND gate in the M113 module in slot B29. This logical combination is then transmitted to the BAI5 unit. This modification causes the same results as the original "LTø3 TTO SKIP" signal, but only when the Versatec is actually ready to accept another character.

Figure 2.b shows the changes that are necessary in the teletype connector (W078 module) shown inthe DEC print LT15-A- 92 . The current loop that was originally operated bv a teletype keyboard" is kept closed by a short for Versatec operation, since it does not have a keyboard. 


\section{Versatec Printer I/O Handler}

An I/O device handler for the Versatec operating in the serial printer mode was written to run in the Advanced Monitor Software system. Instructions for writing the handler and definitions of the different macros it responds to were taken from the DEC publication "Advanced Monitor Software System for PDPI5/ 20/30/40". Appendix 1 is a summary of the Versatec serial printer handler that is in our system library as VSP.

\section{Acknowledgement}

The writer wishes to thank R. T. Brodaczynski for his help in fabricating and debugging the interface. 
Central Processor with 16,384 Word Core Memory Background Teletype

Foreground Teleype

Foregound Teletype Controller

High Speed Paper Tape Reader and Punch

Extended $\Lambda$ rithmetic Element

Automatic Priority Interrupt

Memory Protect

Real Time Clock

Dectape Controller

Four Dectape Transports

Table 1. PDP15/30 Computer system 


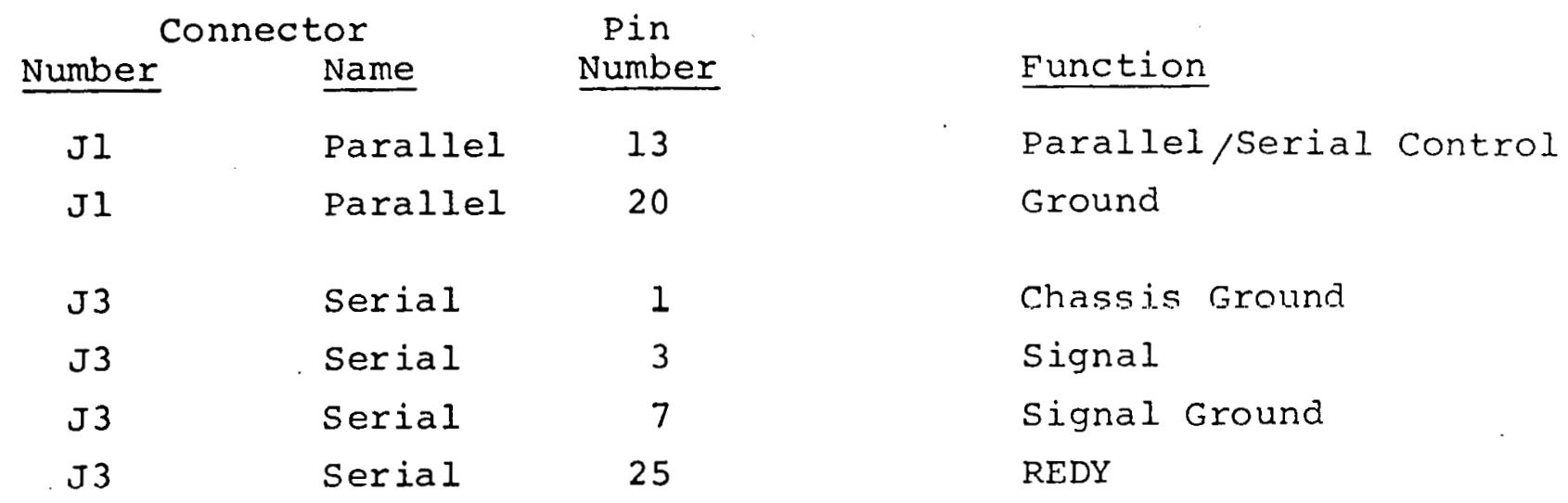

Table 2. Versatec Connector Pin Assignments 


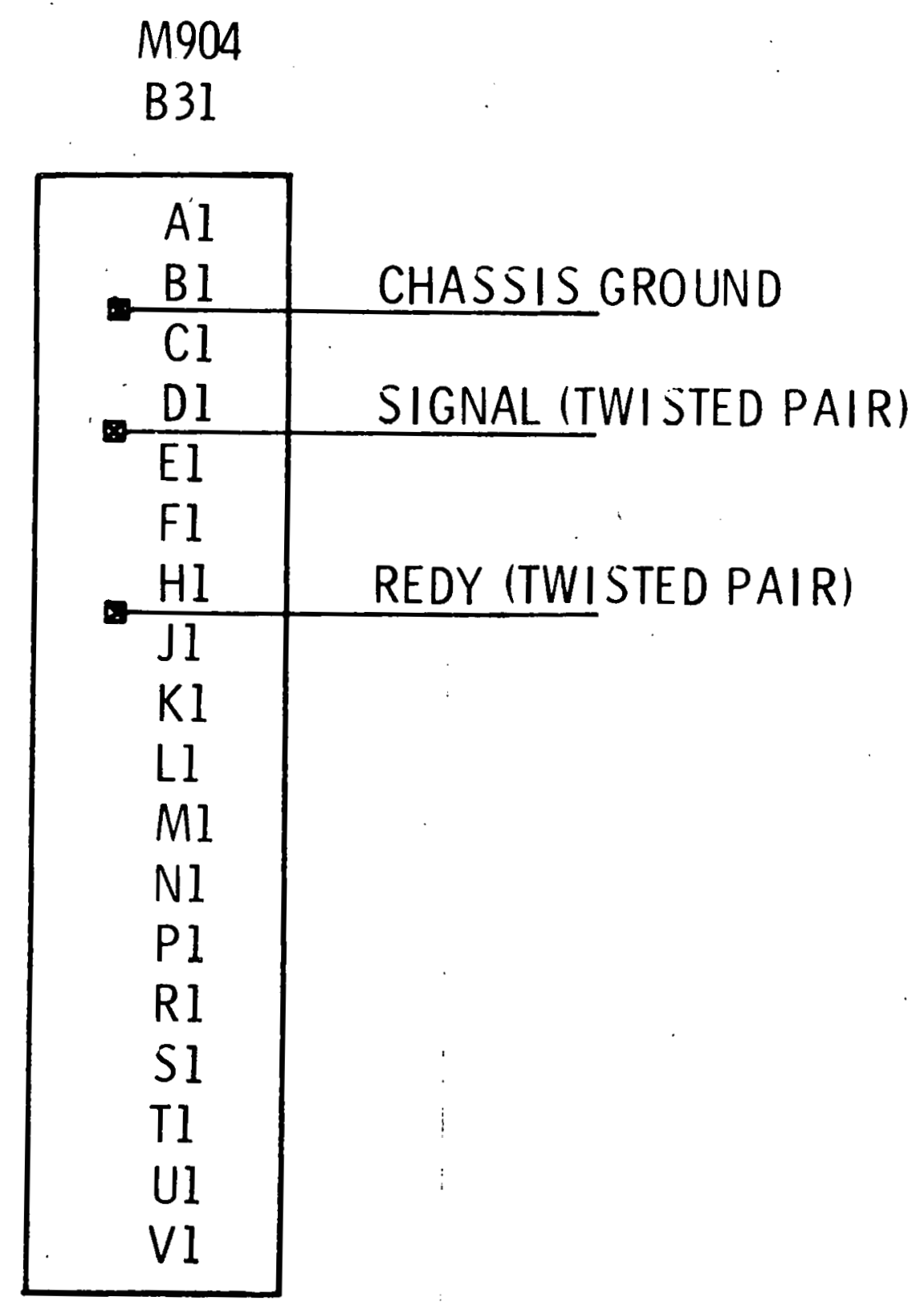

FIG. 1. VERSATEC INTERFACE CABLE CARD WIRING 


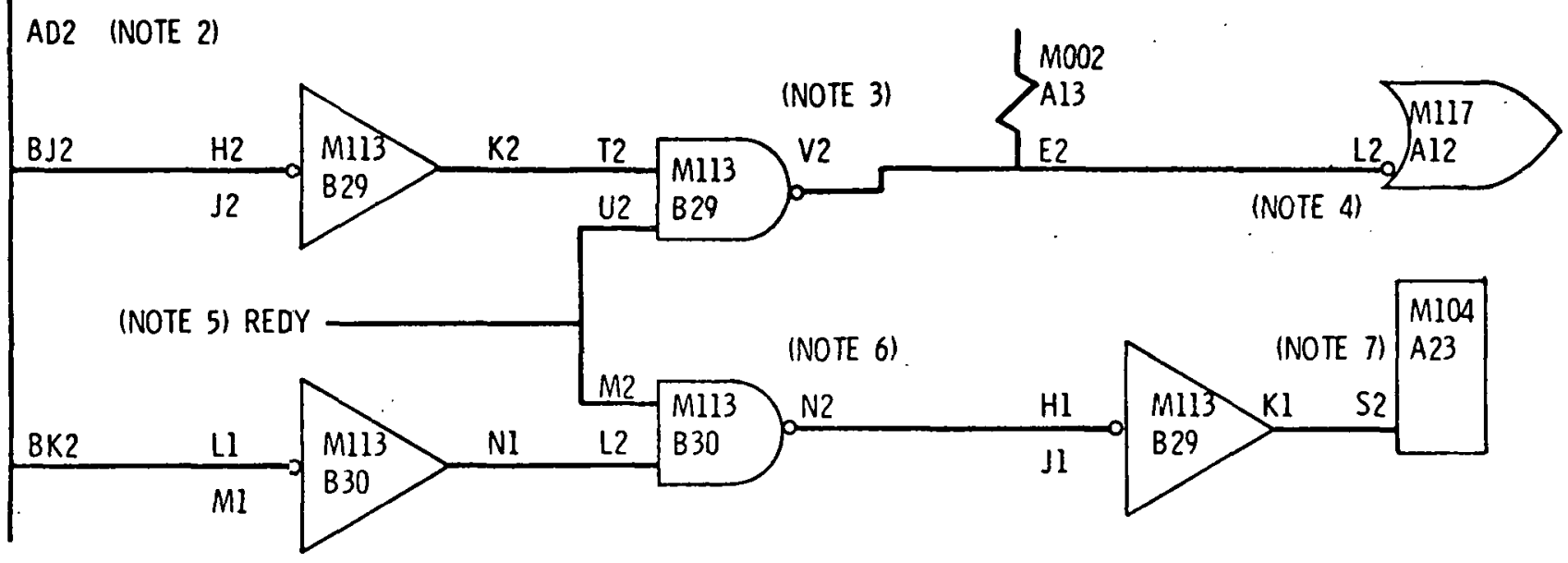

NOTE 1. PDP15 REFERENCE SCHEMATIC - LT15-A-03

NOTE 2. SIGNAL TD M9O4, B31

NOTE 3. THIS SIGNAL IS THE LOGICAL AND OF LTO3 TTO SKIP LILT15-A-03) AND REDY, THE SIGNAL FROM THE VERSATEC

NOTE 4. BEFORE MODIFICATION, LTO3 TTO SKIP L CONNECTED HERE (PDP15 REFERENCE SCHEMATIC BA15-0-05)

NOTE 5. REDY FROM VERSATEC CABLE CARD, M904, B31

NOTE 6. BEFORE MODIFICATION, LTO3 TELEPRINTER FLAG L CONNECTED HERE (PDP15 FEFERENCE SCHEMATICLT15-A-01)

NOTE 7. BEFORE MODIFICATION, LTOI TELEPRINTER FLAG H CONNECTED HERE (LTIS-A-0I) 


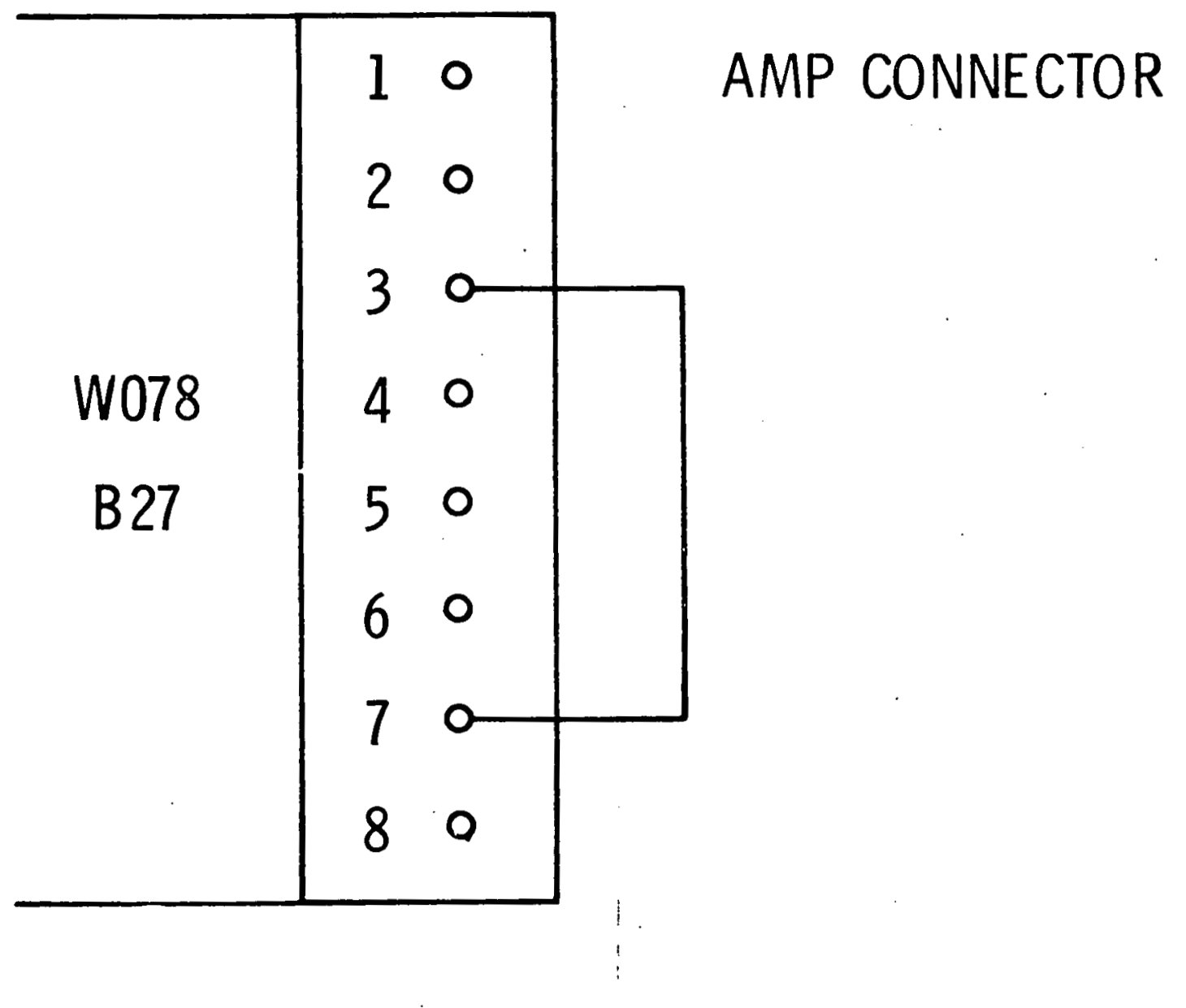

FIG. 2.b LTT5 AND BAI5 WIRING CHANGES 
Appendix 1. Summary of the Versatec Serial

Printer $I / O$ Handler Features

\section{Functions}

\section{I/O Macros}

- INIT

- DLETE

- RENAM

- FSTAT

- SEEK

- ENTER

- CLEAR

- CLOSE

- MTAPE

- READ

.WRITE

\section{Handler Response}

a) Return standard line buffer size (3410)

b) Setup automatic priority interrupt channel register 748 and prọram interrupt skip seciuence.

c) Output one blank line with a carriage return code

Ignored

Illegal function

Ignored

Ignored

a) Allow previous output to terminate

b) Output from feed

c) Allow form feed to terminate

Il legal function
a) Allow previous output to terminate
b) Output a line
c) output a form feed if page is full 
.WAIT, .WAITR
a) If I/O underway, return to the -WAIT call or to the address specified by . WAITR.
b) If I/O finished, return after the .WAIT or .WAITR call.

\section{Legal Data Mode}

IOPS ASCII

III. Vertical Control Characters
a) Carriage return (CR) or line fine ( $L F$ ) causes same result as a CR/LF combination on a teletype and terminates the line.
b) Form feed causes paper to advance to the top of the page.

IV. Horizontal Control Character

A horizontal tab causes $\mathrm{N}$ spaces to be printed, where $\mathrm{N}$ is the number necessary to start the next character in columns $9,17,25,33, \ldots \ldots$

V. Recoverable Errors - None

VI. Unrecoverable Errors
a) Illegal Function - A monitor error message is generated - . IOPS $06 \mathrm{XXXXXX}$ - where XXXXXX is the address of the error CAL.
b) Illegal Data Mode - A monitor error message is generated - .IOPS $07 \mathrm{XXXXXX}$ - where XXXXXX is the address of the error CAL. This is caused by any mode other than IOPS ASCII.
c) . INIT Flat Not Cleared - A monitor error message is generated - . IOPS 37.
d) Illegal Interrupt - A monitor error message is generated - .IOPS 47 .

VII. The Versatec printer in the serial-mode is interfaced via the LT15 and thus has both automatic priority and program interrupt available. 
TITLE WEF.

GLQEL VEF

MSF =IDFE UEFSATEC ANGEFIALA: FFINTEF HAHILEF

COHTEOLLEF IS MOIIFIED LTIS

IEECIMAL HO. OF WOEDE= ST 1

A. F. KOEDEDK $12<1 \mathrm{~B} 73$

CALLIHG EEMUEHEE:

\begin{tabular}{|c|c|c|}
\hline 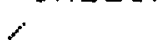 & & \\
\hline , & EHL + IHAT & ELOT $(E T T S \quad 9-17)$ \\
\hline 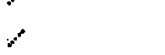 & HEFIM & 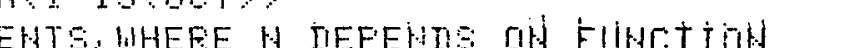 \\
\hline & HOENAL & 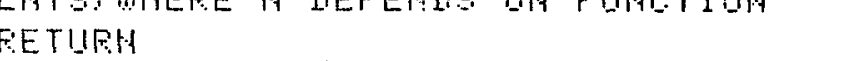 \\
\hline YFT $E F=$ & 34961 & SEIF OH TEAHENIT FLAG \\
\hline YFTEF =7 & 9463 & CLEAE TEAHEHIT FLAL \\
\hline YFTL $\Xi=7$ & 94964 & LDAD TFAHSHIT EUFFEF \\
\hline$. M E D=3$ & & MUHITOF EFEOF IIAGHOETID \\
\hline 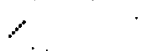 & & \\
\hline$\therefore$ HEIAE & $-E S$ & \\
\hline EHFPHT & G & FUIHTS TO UHFACKEI $5 / 7$ EHE. \\
\hline D:HF 1 & . ELDEK & 5 UHFACKEN 57 CHES. \\
\hline CLEH & 9 & EHFLIHE CHTE. \\
\hline EHELH & 9 & COUHTS HO OF IHHFAEKED 57 CHFE. \\
\hline MIFF & IIEE: & HO. DF SFHEES TO HST FIELI \\
\hline HEHLE & $\begin{array}{l}79 \\
\text { DET }\end{array}$ & HH. DF EHES. LH. \\
\hline IFLG & 77 & GLEAR UHEH IHIT COHFLEHE \\
\hline IHTFLE & 田 & SET DIH AFI DE FIE IHTR. \\
\hline LEAD & E & FHTFE TO HSEF:S LH. EUIFF \\
\hline LHEHT & Q & HO. DF LIHES EETWEEH FF \\
\hline DUIF & 9 & DUTFUT UHIEFUAO FLAG \\
\hline SFEH & 9 & HO. OF SFALES CHTR. \\
\hline TMF 1 & E & TEMF STQFALE \\
\hline WFAELF & 9 & CAL AFIG. FHTF. \\
\hline WFEALF & 日 & EAL EHTFY FHTP. \\
\hline YFOUIT & 9 & IHIIFEET IHTEFFUFT EETIEHA \\
\hline WFSWAE: & 9 & $A D$ \\
\hline $\operatorname{liFC}$ & 日 & WOEI FAIF DOUHTES \\
\hline WFEHT & B & LUSEF'S UOFI FATF COUHT \\
\hline UTFLG & E & CEET IF WAITF:ELEF IF WAIT \\
\hline$A \subset Z$ & Q & TElHF, STMFE FDF: \\
\hline Sc: 1 & 田 & AFE SUEFDUTIHE \\
\hline (i) & 日 & 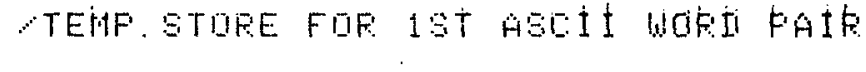 \\
\hline$\forall \subseteq F$ & IIAL: & WFEALF SAUE CAL FUIHTEF \\
\hline & THE & WFAFEF SQUE AFE. FOIHTEF \\
\hline & ISZ & WFAEEF FOIHT TO FUHETIOHA \\
\hline & LAC: & WFAERF VEET FLIHCTIDH \\
\hline & AHD & FEMOUE FOESIELE LiHIT HO. \\
\hline & $I S z$ & WFAEEF FOIHT TO HEYT ARE. \\
\hline & TAD & CINF DSFEH \\
\hline & IIAE: & DEFLH \\
\hline DSFCH & . & LISFATEH WITH WOD UHF \\
\hline & IMP & VFIHIT 1 . IHIT \\
\hline &. $\mathrm{imF}$ & WFICHI 2 . FSTAT. LIELET; FEHAH \\
\hline & $M M F$ & YFEFES \\
\hline &.$M F$ & WFIBHI 44 . EHTEF: \\
\hline & $M P$ & YFILHE \\
\hline & IMF & YPELDS E . ELOSE \\
\hline &. $\mathrm{MF}$ & WFILHE $\because$ DTAFE \\
\hline & JMP & YFEFBE 10 . REAI \\
\hline
\end{tabular}




\begin{tabular}{|c|c|c|c|}
\hline JNF & UPleIt &, 11 & WFITE \\
\hline$M M F$ & WFWAIT & 12 & WAIT \\
\hline $\operatorname{IMP}$ & YFERQG & 13 & TFAli \\
\hline$M \mathrm{~F}$ & YFEPGE & 14 & EFFOF \\
\hline $1 \mathrm{MF}$ & YFEFQE & $\therefore 15$ & EEROR \\
\hline IMF & YFERE & 16 & EFEOR \\
\hline INF & YFEFEE & 17 & EFPOF: \\
\hline
\end{tabular}

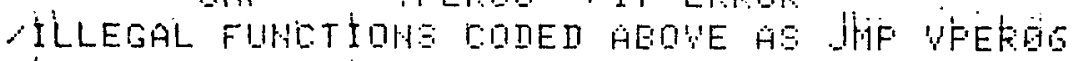

ILLEGAL FUHETIOH
LFEREE Lal!
LATPEOR COUE $E$

ILLEGAL DATA MIITE

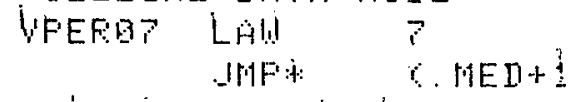

CIHIT HOT COHFLETE

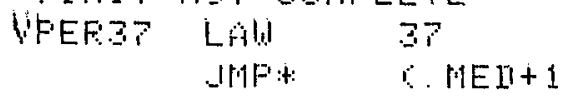

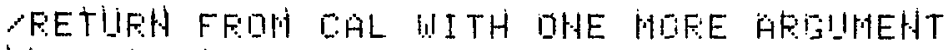

WFICHI ISZ WEFEF

HOFMAL FETHFH FEOM DAL

VFIGHZ DEF PEFEGK FFOH LEUEL 4

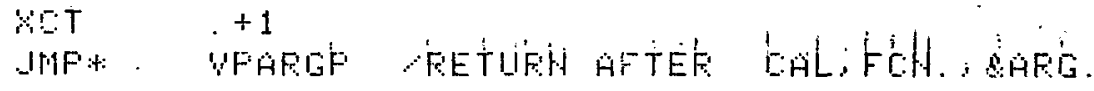

$\gamma$

I INIT EOLITIHE

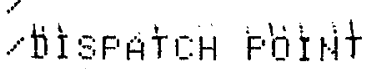

UFIHIT=ELF DA FIRET EHTEY AHII AFTEF CLOE

=HLF DH GUESEDUEHT EHTEIES

UFIHT EKF

$$
\text { MNF HTFT }
$$

CHECK IF DUTFUT UHDERLAH
LAE DUFE
SZA
MA HTF TEYHES HHT

AFEST EHTFY DR AFTEE CLOSE

CHAHIEE TI HOF
LAC:
IAC
11211
I 52
choF
VPIHIT
LHCHT CLEAE LIHE LHTFE

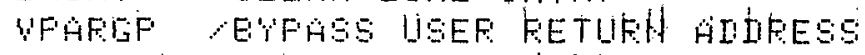

REtLFH STAHTART LIHE EUIFFEF SIZE TO USEF
LABE:
642
IIEL 34
IIAL: WFAFIIF

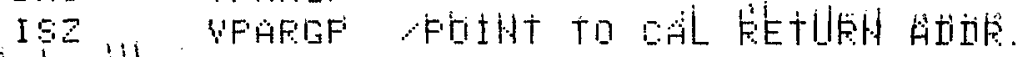

$\triangle$ SETIF AFI HHIII FIE

EHL I4 LTIS AFI AIIF.

IE IOFE FUHCTIOH DOIE

UFTSF BVIF IOT TO TEST FLAG

YFIHT AHTEREUFT AIIIFE

SET IHTEFEUFT FOIHTEF TO. IHIT-EF

LAE $\quad$ SHF CLEIIO

DAE HHTFHT

$\angle$ SET . IHIT FLAL

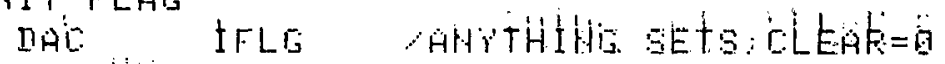

"ET OLITFUT UHADEFUAY' FLAG

gouTfut IER

IIAC DIIFE

$\begin{array}{ll}\text { LRH } & 15 \\ \text { WHS } & \text { USOFT }\end{array}$




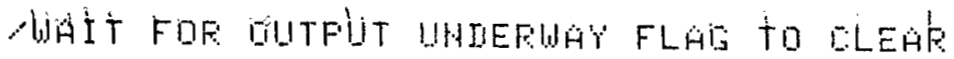

LAE DUFG.

S2A

IMF $\quad-2$

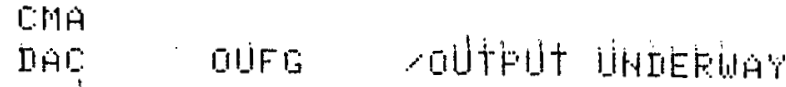

Lali 12

Jis velpt routfult LF

LAE GUFG UATTFQF LF TOFIHISH

SZA

INIF.-2

TEETUER AFTER CAL

NEII IFLG

IHF WFIEHE

AHO FIFET THHE IHTO. IHIT

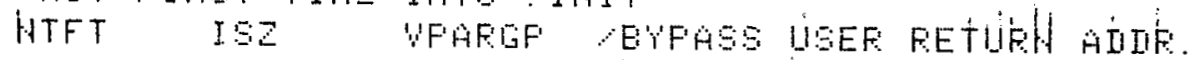

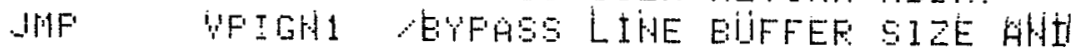

JWF HERE FFOM IHTEREUF'T

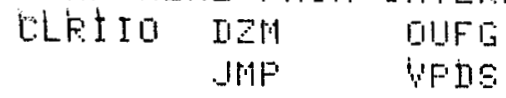

S. RLESE FOLLTINE

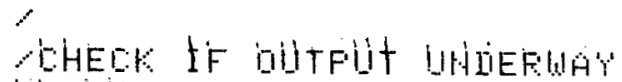

WFELES LAE BUFI

SHA

SETHRH to baL-HOd IT DUEF

Díur DER JEEAK FFOH LEVLL 4

SOT TMF TFEAF HO DAL GUER

SOLTFUT HOT LHDEFUAY

DHTO LAE G.JMF LKCLES

DAL IATFHT SET IHTE FHATE.

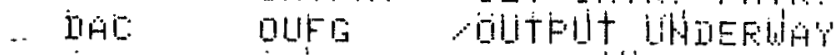

TIAD: IFLG SET IHIT FLAG

LALI 14

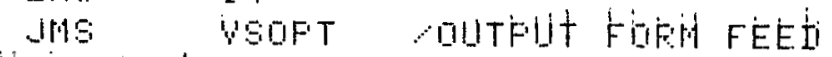

WAIT FUE TOF DF FAGE

LAI: DUIF

$32 A$

JMF $\quad-2$

CRESTORE. IHIT EHTE'Y

LAC $\quad$ SEF

CLEAR LIHE DOLHTEF:

IIZM LHEHT

FETURH AFTER EAL

JMF UFICHE

SHF HEFE FROA IHTR.

CKCLES DZH DUFG

JMP VPDS

JRItE RUUTHAE

GFLRIT LAE DIJFI

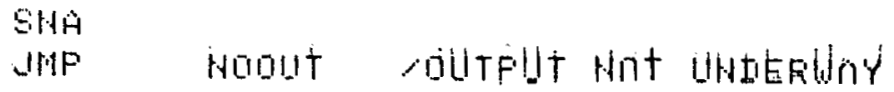




\section{OULTFUT UHEEFUAY}

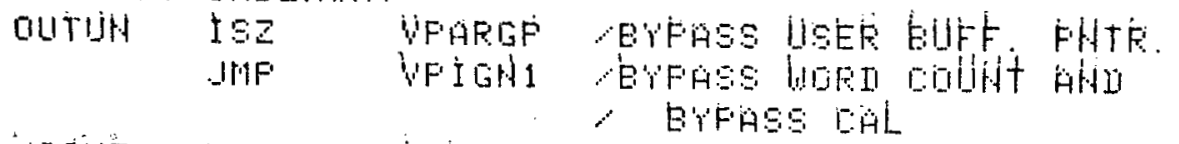

IOOUIT LAL IFLG

SZA

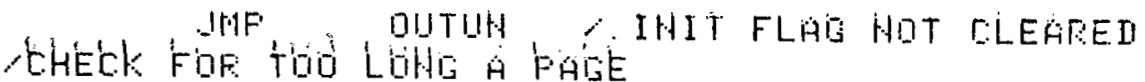

$$
\begin{array}{ll}
\text { LAC LHCHT } \\
\text { SAD } \\
\text { GHS FOL }
\end{array}
$$

\begin{tabular}{|c|c|}
\hline LÂl & 7000 \\
\hline AHn:t: & WFEALP \\
\hline EAII & C20日G \\
\hline IrifF & $\therefore$ \\
\hline
\end{tabular}

THATA HOIE IH LALCEITS E-E)

TLLEGal tiata MODE

DATA MOIIE OK.

VFEFET

CGET USEE'S LIHE EIIFF. FHTF.

$$
\begin{array}{ll}
\text { LAEN } & \text { WAAGP } \\
\text { IHE: } & \text { LEAI } \\
\text { ISZ } & \text { WAEGF } \\
\text { ISZ } & \text { WAAGEF }
\end{array}
$$

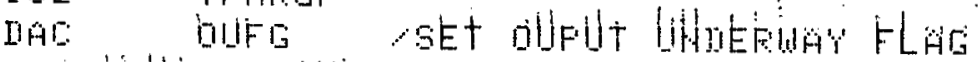

REABLY TO OUTFUIT A LIHE

LET LISEF'S WFE

VSFH LALI:

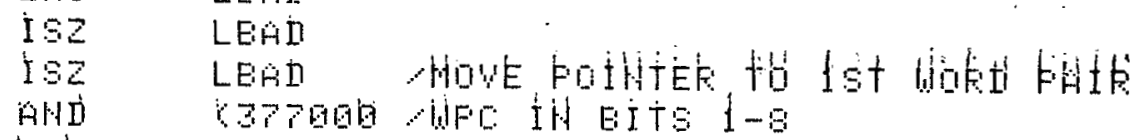

ELL

HS AFS

11

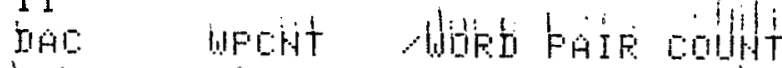

LAL:

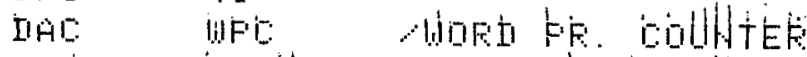

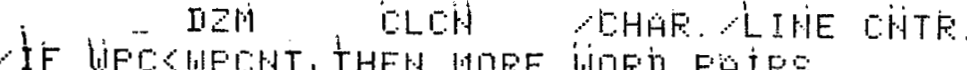

CUFEHT. THEH MORE WOFE FHIRS

EKUP LAE UFENT

$$
\text { SAI UFE }
$$

\begin{tabular}{|c|c|}
\hline LAC: & LEAII \\
\hline IAID: & 101 \\
\hline $15 z$ & LEAI \\
\hline LAC: & LEAD \\
\hline PिA & जTH RHP H EITS $1-1 \%$ \\
\hline IIE: & EHF $1+4$ \\
\hline $\begin{array}{l}\mathrm{J} M \mathrm{~S} \\
\mathrm{r}\end{array}$ & AFS \\
\hline DAL: & ATH CHR IH BItS \\
\hline $\begin{array}{l}\text { IMS } \\
\vec{P}\end{array}$ & AES \\
\hline Anti & -1 \\
\hline
\end{tabular}$$
\text { INF WFEF: }
$$

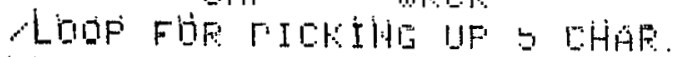

CHOT LAL HEHLE HAHILEE CHAE LIHE EOUIT

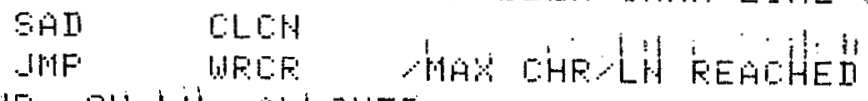

MUEE DHF OH LH. ALLOUEJI

CDET 5 MGEE DHFS. 


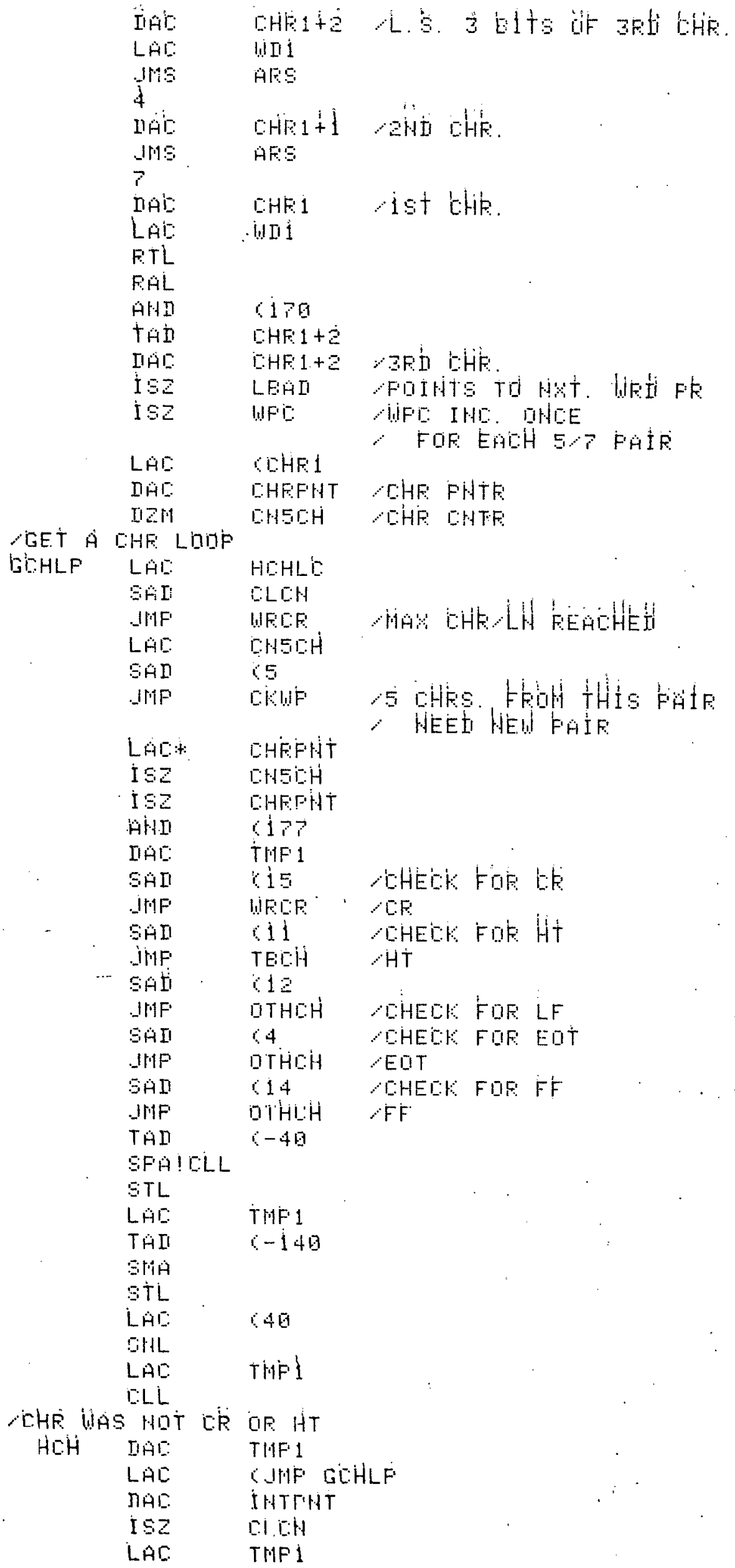




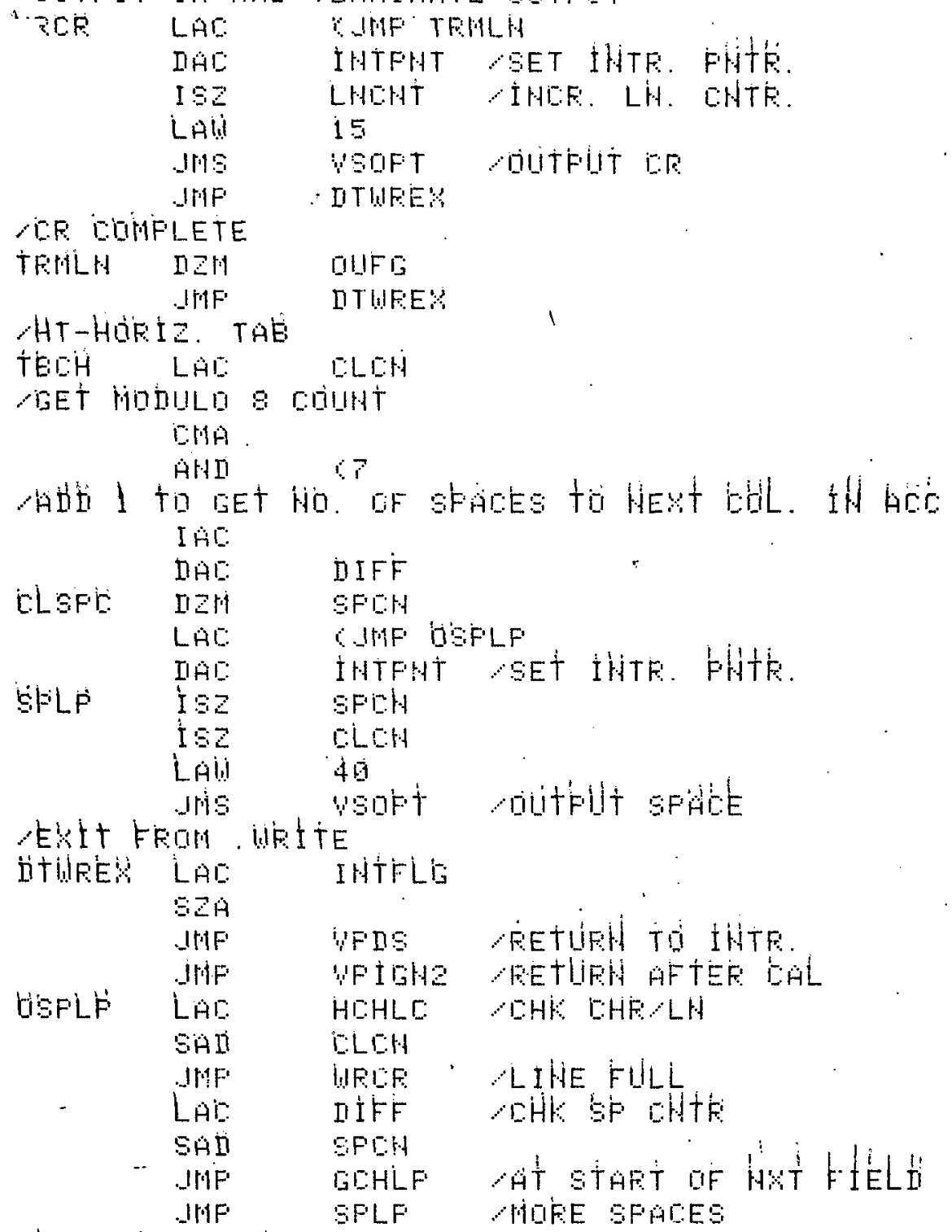

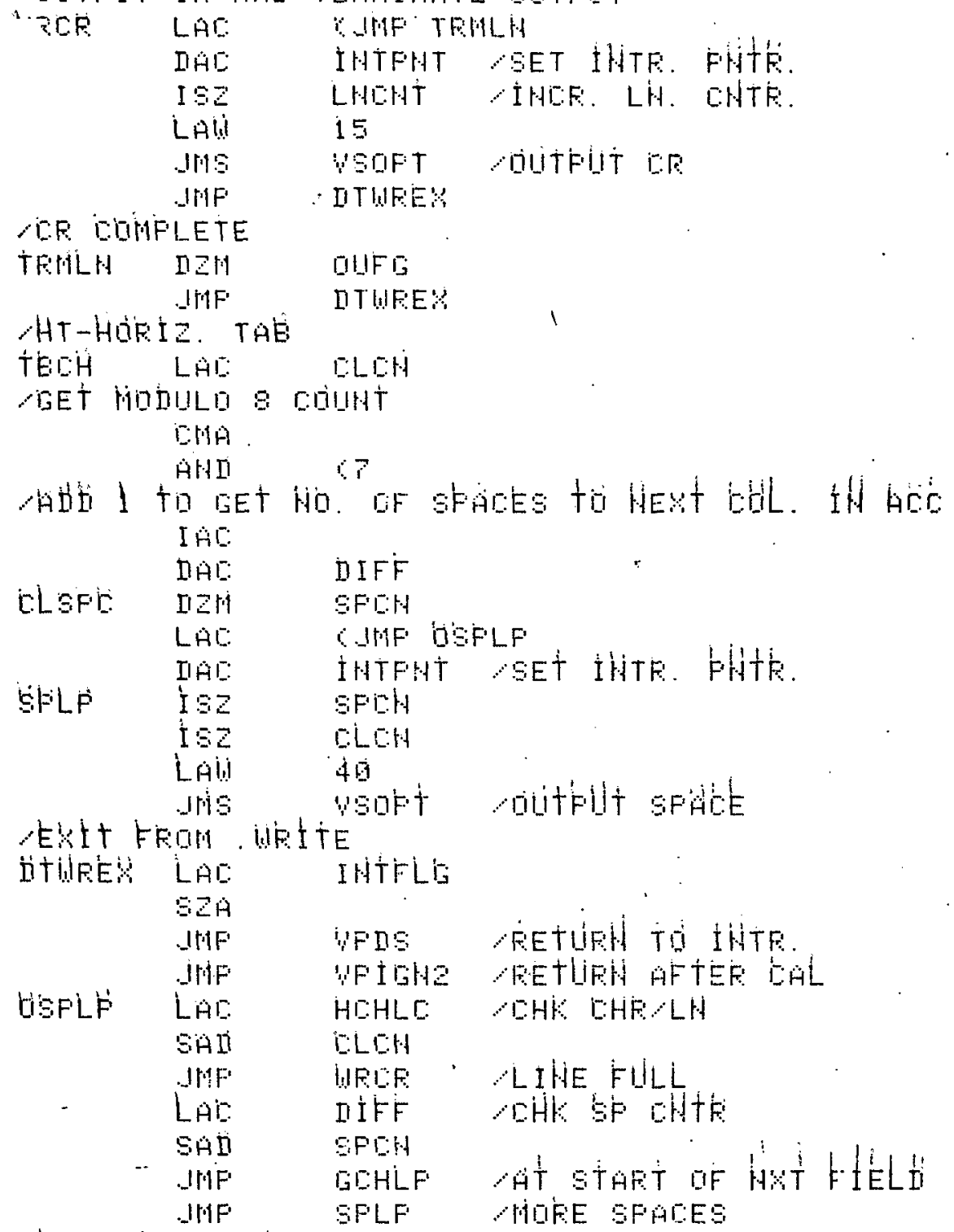

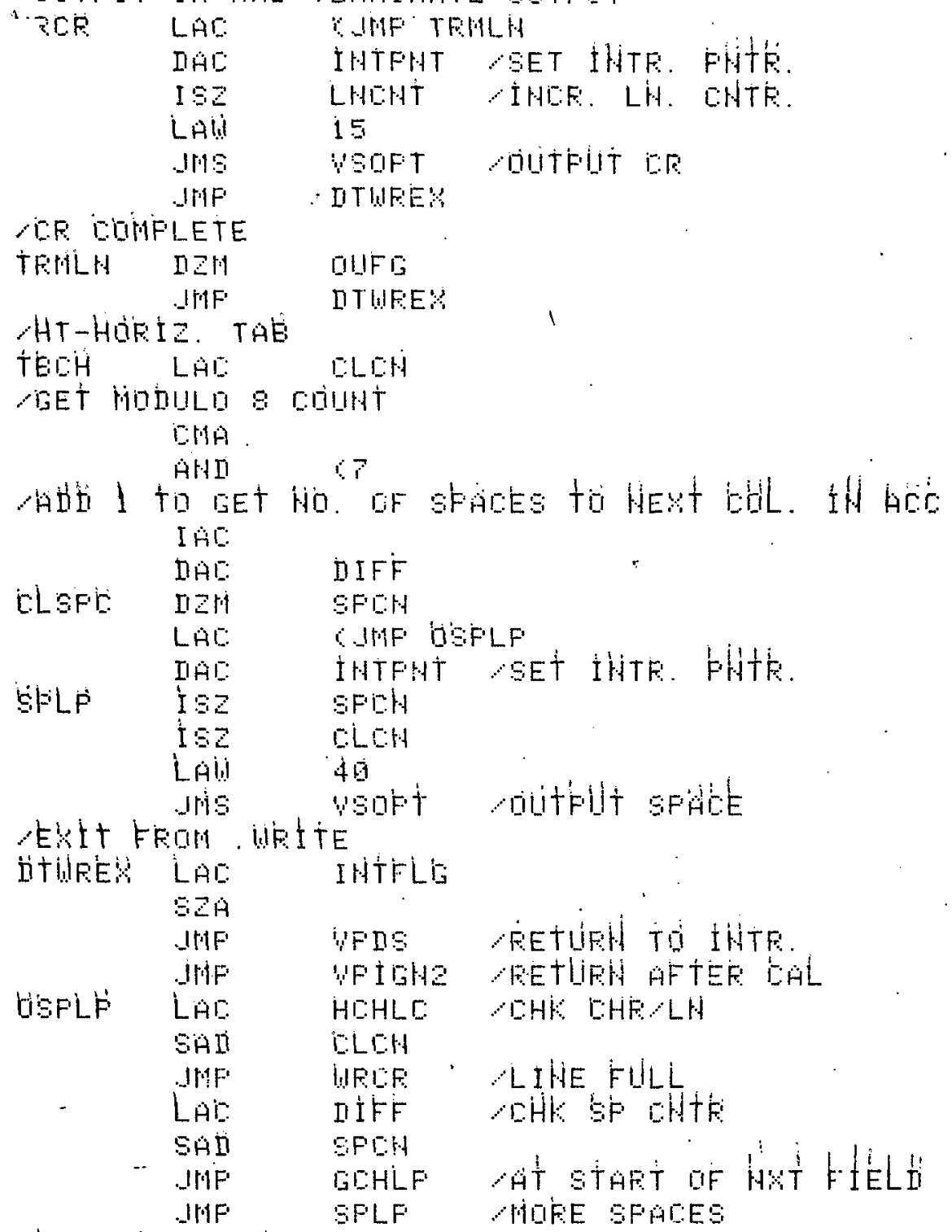

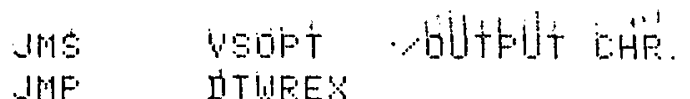

-OUTFUIT EF AHI TEFHIHATE DITFIIT

ARGE TOD LiHG

IHSEFT FDFA FEEI

Fiti

\begin{tabular}{|c|c|}
\hline LAE & CUAF tKAFF \\
\hline DAE & IHTFHT \\
\hline DAE & DIIFE \\
\hline Lalu & 14 \\
\hline 145 & YEOFt \\
\hline LAL & DUFE \\
\hline$S 2 A$ & \\
\hline IHiF & -2 \\
\hline 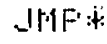 & FETL \\
\hline IEEA & OUIF \\
\hline Ittif & WDES \\
\hline
\end{tabular}

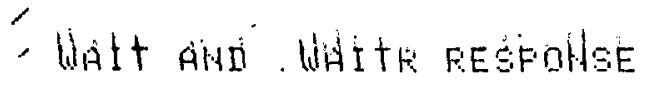

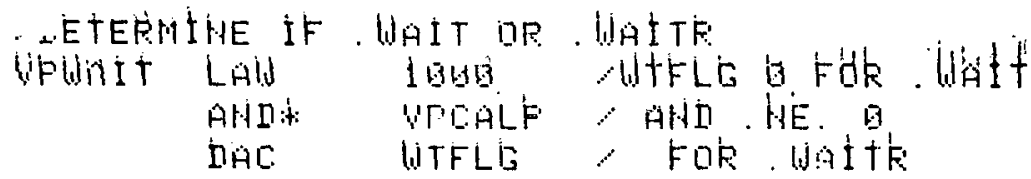


AHELK FOR DUIFUT BHDERAY

LÄ DISG

SHA HeS hlot eller

biley

AHd EUSY

LAC UTFLE

$\sin$

JMF WTEE WAITE

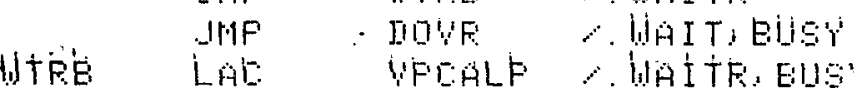

LAE WFELF WAITREUEY

AHI C7GEGG L. EN, HF

RAE: UFCALF

LAC $\quad$ PAPGF

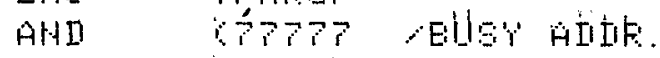

BQR VFLALF

DAC VFCALF

INF TOUE

$H E S Y-L D C$

LHE WTFLG

ISE UFAREF , INATTE

IMP UFItitz

Nibit

OUITPUT Chrs. To frihter.

VALLTHIS SEQUEHEE:

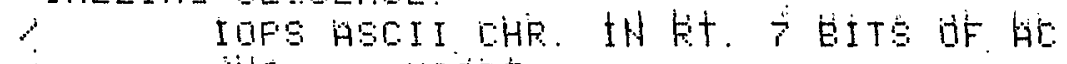

$\therefore$ jis Wert

GeGFT

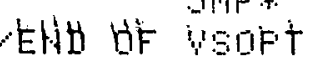

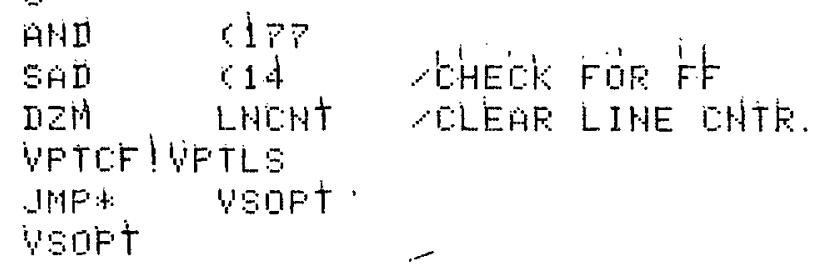

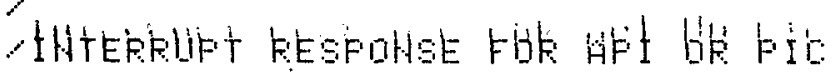

Write naE Grovac sâE AL

LAC: 6 G

nAE UFQUT SAUF FELLER HF

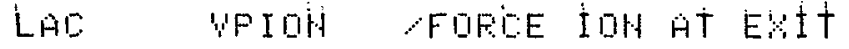

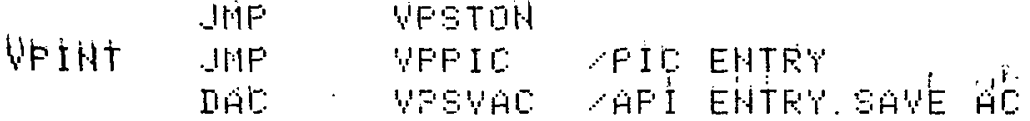

LAC VFIHT

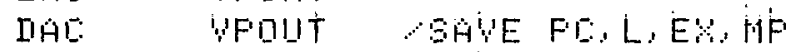

IOFS PRHECK FIE, STATIVS

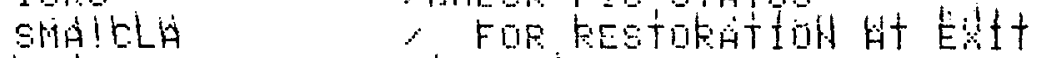

LALI 17849 L IOF:EITE=

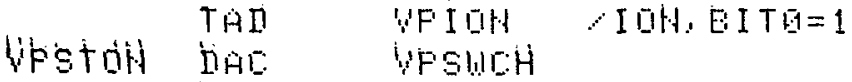

UotoH WFTCF CLEAR TEAHEHIt Flat IOH FHAELE FIE

nac IHTFL SET IHTR. FLä́

HLT IHTE FHTR CHAHGED TO

IIISMISS FROH IHT.

JHF BY SEINENTS THAT DUIFUL 


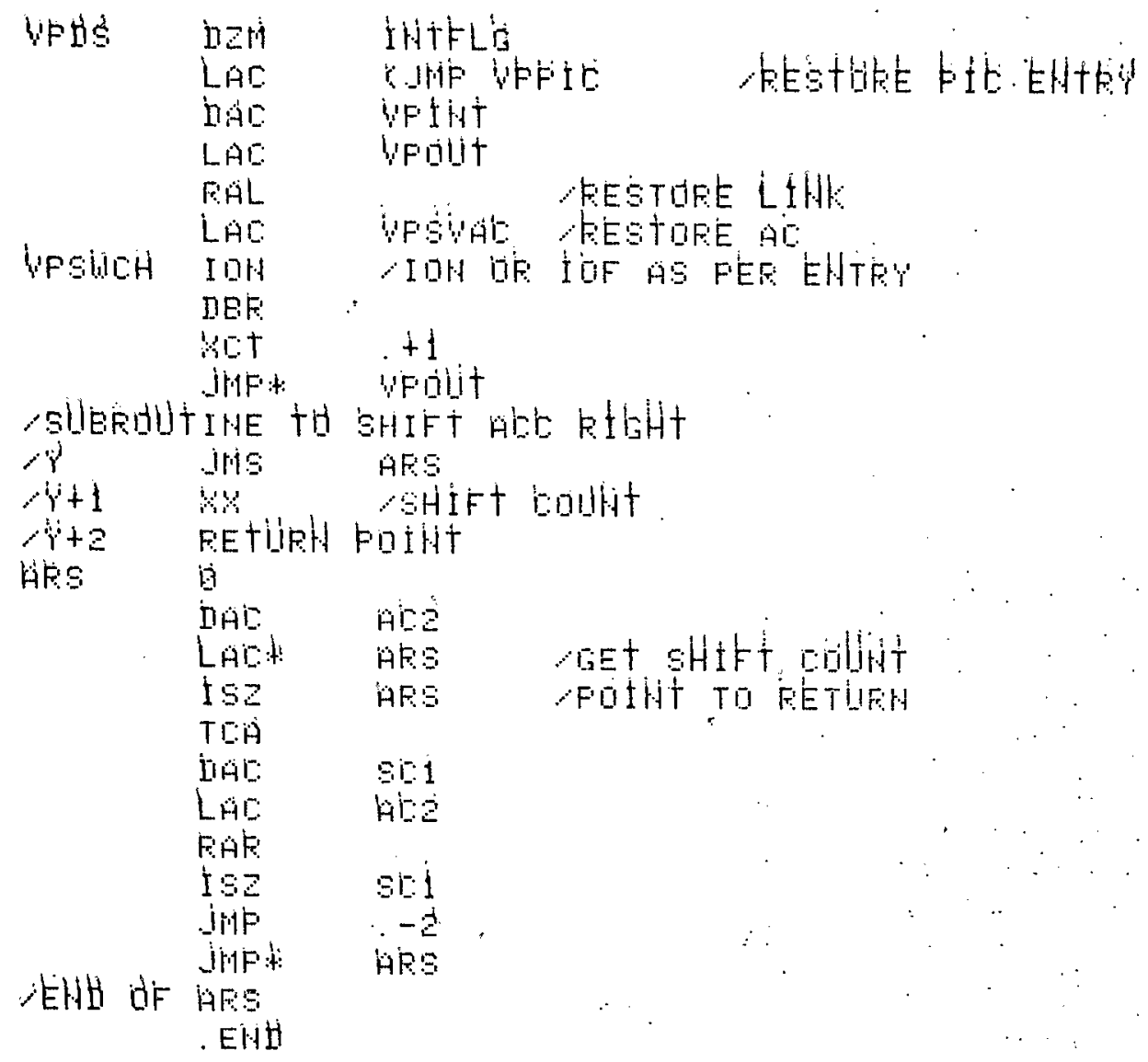




\section{DISTRIBUTION}

J. M. Nielsen

R. W. Perkins

R. T. Brodaczynski

D. L. Mayfield

W. A. Mitzlaff

C. A. Ratcliffe

J. R. Kosorok (10) 